\title{
Expression of Isocitrate Dehydrogenase-1 (IDH-1) Mutant Protein in Gliomas
}

\author{
Jaiswal $\mathrm{S}^{1 *}$, Chaudhary $\mathrm{N}^{1}$, Prasad $\mathrm{P}^{1}$, Khatri $\mathrm{D}^{2}$, Das $\mathrm{KK}^{2}$, Mehrotra $\mathrm{A}^{2}$, Jaiswal AK ${ }^{2}$, Pal $\mathrm{L}^{1}$ and Behari $\mathrm{S}^{2}$ \\ ${ }^{1}$ Department of Pathology, Sanjay Gandhi Postgraduate Institute of Medical Sciences, India \\ ${ }^{2}$ Department of Neurosurgery, Sanjay Gandhi Postgraduate Institute of Medical Sciences, India \\ *Corresponding author: Sushila Jaiswal, MD, Additional Professor, Department of Pathology, Sanjay Gandhi Postgraduate Institute of Medical Sciences, \\ Rae Bareli Road, Lucknow 226014 UP, India
}

Submission: February 21, 2018; Published: March 09, 2018

\begin{abstract}
Background and aim: Isocitrate dehydrogenase-1 (IDH-1) mutation in gliomass has diagnostic and prognostic significance. The aim of this study was to determine the IDH-1 mutation in gliomas and their correlation with various clinical parameters.

Material and methods: One hundred cases of gliomas were studied for IDH-1 expression by immunohistochemistry (IHC).

Results: IDH-1 mutation was expressed in 36\% (5/14) of children (age < 16 years) and 53\% (46/86) of adults (age >16 years). History of seizure was significantly associated with IDH-1 expression. Frontal location of tumor and absence of contrast enhancement were significantly associated with IDH-1 expression ( $\mathrm{P}=0.23$ and 0.001 respectively). IDH-1 positivity was noted in $47 \%$ (29/62) astrocytic tumors, $100 \%$ (3/3) oligoastrocytic tumors, $79 \%$ (15/19) oligodendroglial tumors and 25\% (4/16) ependymal tumors. Overall, IDH-1 mutation was positive in 51\% (51/100) of gliomass. IDH-1 expression was significantly higher in WHO grade II and grade III gliomas (67\% each) as compared to WHO grade IV and I ( $35 \%$ and $27 \%$ respectively).

Conclusion: IDH-1 mutation occurs in overall 51\% of gliomas. History of seizure, frontal location and absence of contrast enhancement on radiology are significantly associated with IDH-1 expression. IDH-1 is expressed mostly in oligoastrocytic tumors followed by oligodendroglial tumors, astrocytic tumors and least expressed in ependymal tumors. WHO grade II and III gliomass are more common to have IDH-1 expression than grade IV and grade I tumors.
\end{abstract}

Keywords: IDH-1 mutation; Gliomas; Immunohistochemistry; Astrocytic tumors

Abbreviations: IDH-1: Isocitrate Dehydrogenase-1; IHC: Immunohistochemistry; ICP: Intracranial Pressure; CNS: Central Nervous System; WHO: World Health Organization; MGMT 06-Methylguanine-DNA MethylTransferase; EGFR: Epidermal Growth Factor Receptor; TCA: Tricarboxylic Acid; PCR: Polymerase Chain Reaction

\section{Introduction}

Tumors of central nervous system (CNS) are uncommon neoplasms and comprise $1-2 \%$ of all the malignancies [1]. gliomas, the most common tumor of the CNS arise from the glia, the supporting cells of the central nervous system. Astrocytes, oligodendrocytes, and ependymal cells are types of glial cells that may give rise to astrocytoma, oligodendrogliomas, and ependymoma respectively. According to World Health Organization (WHO) 2007, these tumors are graded into four grades according to specific histopathological criteria and their biological behaviour ranging from grades I to IV. Glial neoplasmss develop as a result of genetic alterations that continuously accumulate with tumor progression. Molecular signatures of these tumors play roles as diagnostic, prognostic, and predictive markers and influence the clinical decision making process. Various genetic alterations described in the literature include $1 \mathrm{p} / 19 \mathrm{q}$ co-deletion, 06-methylguanine-
DNA methyltransferase (MGMT) promoter hypermethylation and epidermal growth factor receptor (EGFR) alterations. The recent discovery of mutations of the isocitrate dehydrogenase- 1 (IDH-1) gene in gliomas, in particular WHO grade II astrocytic, oligodendroglial, oligoastrocytic gliomass, and WHO grade III astrocytic tumors, is pointing toward a potentially common initiating event within this diverse group of tumors. Gliomass harbouring this mutation have been found to be associated with favourable prognosis [2,3].

The objective of the present study was to determine the frequency of IDH-1 mutant protein in different grades of gliomass by evaluating IDH-1 mutant protein expression in tissue specimens of gliomass by immunohistochemistry (IHC) and to determine the clinical correlation (age, sex, duration of symptoms and tumor location) with immunohistochemical expression of IDH-1. 


\section{Material and Method}

In this prospective study one hundred and ten cases of gliomas were included from July 2013 to June 2016. Ten patients were excluded from the study due to inadequate tumor tissue and/or incomplete medical records. Thus total 100 cases were considered for the study. Their clinical details in form of age, sex, duration of symptom, clinical features, radiological findings and operative details were noted. The slides were reviewed and the histological diagnosis was established. Expression of IDH-1 protein was determined by the standard streptavidin biotin peroxidase immunohistochemical method. A strong cytoplasmic staining of tumor cells for IDH-1 protein was scored positive. A negative control slide in which the primary antibody was excluded was considered as negative. Statistical analysis of data was done using SPSS software version 13.0.

\section{Results}

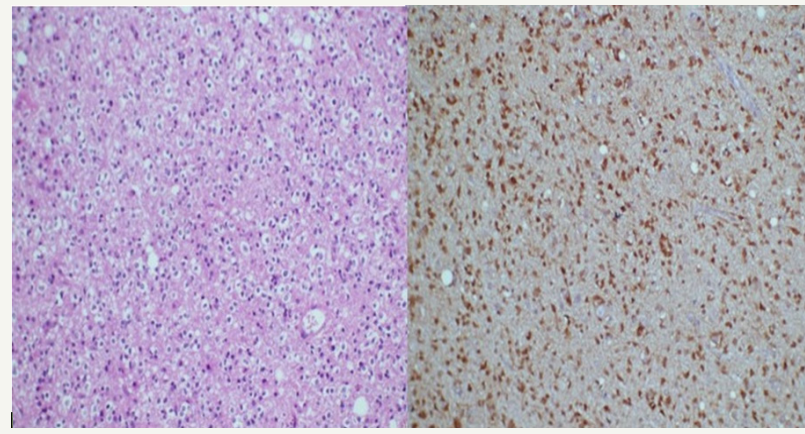

Figure 1: H\& E stained section (200X) shows tumor cells displaying round nuclei with perinuclear halo in fibrillary background suggestive of WHO grade II oligodendroglioma. On immunohistochemistry for IDH-1 (200X) the tumor cells show cytoplasmic as well as nuclear positivity.

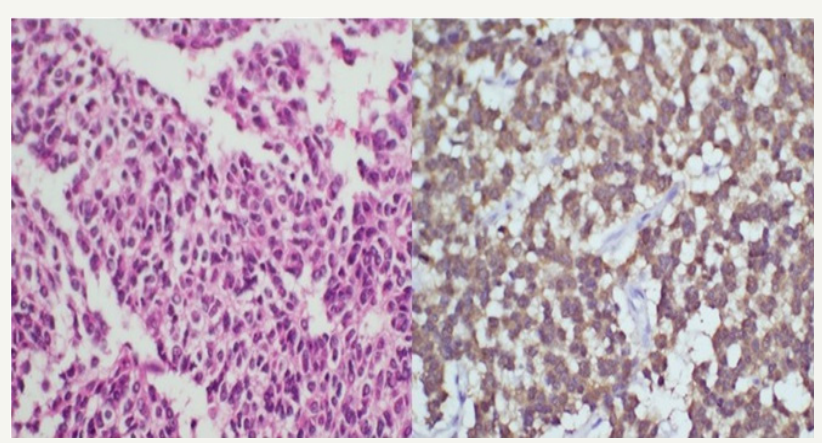

Figure 2: H\& E stained section (200X) shows tumor cells displaying moderate nuclear atypia and few showing perinuclear halo in fibrillary background suggestive of WHO grade III anaplastic oligodendroglioma. On immunohistochemistry (200X) the tumor cells show cytoplasmic as well as nuclear positivity.

Out of one hundred study cases, there were 70 males and 30 females. Age range was 4-75 years with mean age of 33.4 years. There were 14 pediatric cases (age below 16 years) and 86 adult cases (age above 16 years). Duration of symptoms was $<1$ month in 19 cases, 1-6 months in 42 cases and $>6$ months in 39 cases. Most common clinical presentation was seizures $(n=62)$ followed by raised intracranial pressure $(n=54)$ and neurological deficits $(n=41)$. Most common location of gliomas was frontal $(n=28)$ followed by insular $(\mathrm{n}=15)$. In ten cases, tumor was located in the spinal cord. Seventy six patients had tumor size $>6 \mathrm{~cm}$. Gliomas was confined to one lobe $(n=38)$, two lobes $(n=33)$ and more than two lobes $(n=1)$, and was going to opposite hemisphere by corpus callosum $(n=1)$. Gliomas was having contrast enhancement $(n=81)$, intra-tumoral calcification $(n=11)$ and cystic degeneration $(n=40)$. Surgical intervention in form of near total tumor excision $(n=53)$, gross total tumor excision $(n=26)$, tumor decompression $(n=19)$ and tumor biopsy $(n=2)$ was performed. The most common histopathology was astrocytic tumors $(n=62)$ followed by oligodendroglioma $(n=19)$, ependymal tumor $(n=16)$ and oligoastrocytoma $(n=3)$.The most common astrocytoma was glioblastoma $(n=31)$ followed by diffuse fibrillary astrocytoma $(n=15)$ and pilocytic astrocytoma $(n=10)$. Overall, the most common WHO grade of tumor was grade II $(n=42)$, followed by grade IV $(n=31)$, grade I $(n=15)$ and grade III $(n=12)$.

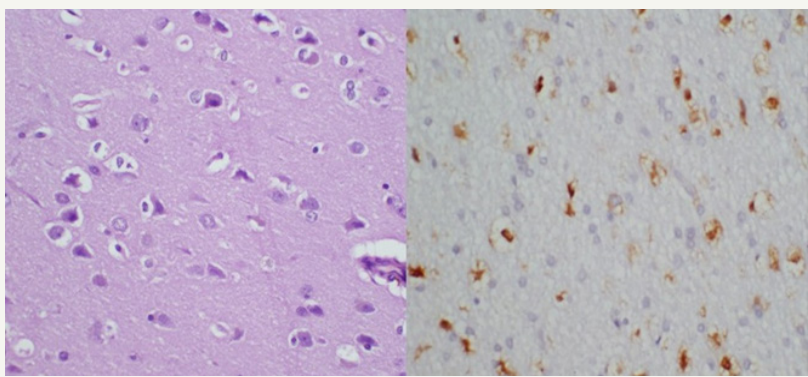

Figure 3: H \& E stained section (400X) shows infiltrating tumor cells from the small biopsy displaying round to oval nuclei in fibrillary background suggestive of WHO grade II fibrillary astrocytoma. On immunohistochemistry for IDH-1 (400X) the tumor cells show cytoplasmic as well as nuclear positivity.

Table 1: Association of IDH-1 expression with demographic variables.

\begin{tabular}{|c|c|c|c|c|c|c|c|}
\hline \multirow[t]{2}{*}{ No. } & \multirow[t]{2}{*}{ Variable } & \multicolumn{2}{|c|}{ Expression } & \multicolumn{2}{|c|}{$\begin{array}{c}\text { No } \\
\text { expression }\end{array}$} & \multirow[t]{2}{*}{ Total } & \multirow[t]{2}{*}{$P$ value } \\
\hline & & No. & $\%$ & No. & $\%$ & & \\
\hline \multirow{4}{*}{1.} & \multicolumn{7}{|c|}{ Age } \\
\hline & $<16$ years & 5 & 36 & 9 & 64 & 14 & 0.217 \\
\hline & $>16$ years & 46 & 53 & 40 & 47 & 86 & \\
\hline & Total & 51 & 51 & 49 & 49 & 100 & \\
\hline \multirow{4}{*}{2.} & \multicolumn{7}{|c|}{ Gender } \\
\hline & Male & 32 & 46 & 38 & 54 & 70 & 0.106 \\
\hline & Female & 19 & 61 & 11 & 39 & 30 & \\
\hline & Total & 51 & 51 & 49 & 49 & 100 & \\
\hline \multicolumn{8}{|c|}{ Chi-square test used } \\
\hline
\end{tabular}

IDH-1 expression was positive in 51\% (51/100) cases of gliomas. On correlating IDH-1 expression with various clinical parameters, it was observed that IDH-1 expression was higher in adults (53\%) and females (63\%) as compared to children (36\%) and males (46\%). However, the difference was statistically not significant (Table 1; $\mathrm{P}=0.217$ and 0.106$)$. It was also noted that cases with longer the 
duration of symptoms had higher expression of IDH-1,than those with shorter duration of symptoms, however, this difference was statistically not significant (Table 2; $\mathrm{P}=0.092$ ). Regarding clinical features, history of seizure was significantly associated with IDH-1 expression $(\mathrm{P}=0.002)$, however, no statistical significant association was observed between other clinical features (raised ICP as well as neurological deficit) and IDH-1 expression (Table 3; P=0.828 and 0.209 respectively). For different sites of tumor location, IDH-1 expression ranged from 25\% (Posterior fossa and parieto-occipital) to $100 \%$ (corpus callosum and orbit), however, this difference was not statistically significant $(\mathrm{P}=0.051)$. On applying Fisher's exact test, frontal location of tumor was significantly associated with IDH1 expression (Table 4; $\mathrm{P}=0.023$ ). Regarding radiological features, cases having absence of contrast enhancement were having higher degree of IDH-1 expression (84\%) as compared to those having contrast enhancement (43\%) and this difference was statistically significantly $(\mathrm{P}=0.001)$. However, no statistically significant association was observed between other radiological features (calcification and cystic changes) and IDH-1 expression (Table 5; $\mathrm{P}=0.127$ and 0.568 respectively). IDH- 1 expression was higher in oligoastrocytic tumors (100\%) and oligodendroglial tumors (79\%) as compared to astrocytic (47\%) and ependymal tumors $(25 \%)$ and this difference was statistically significant (Table 6; $\mathrm{P}=0.002$; Figure 1-3). For different histopathological subtypes of gliomas, IDH-1 expression ranged from $0-100 \%$ and statistically this difference was significant $(\mathrm{P}=0.001)$, however, on applying exact test, IDH-1 expression was found to be significantly associated with oligodendrogliomas only (Table 7; $\mathrm{P}=0.013$ ). IDH-1 expression was higher in WHO grade II and III gliomas (67\% each) as compared to WHO grade IV and I (35\% and $27 \%$ respectively). Statistically significant difference was noted between IDH-1 expression and
WHO grades of gliomas (Table 8; $\mathrm{P}=0.08$ ).

Table 2: Association of IDH-1 expression with duration of symptoms.

\begin{tabular}{|c|c|c|c|c|c|c|c|}
\hline \multirow{2}{*}{ No. } & \multirow{2}{*}{$\begin{array}{l}\text { Duration of } \\
\text { symptoms }\end{array}$} & \multicolumn{2}{|c|}{ Expression } & \multicolumn{2}{|c|}{ No expression } & \multirow{2}{*}{ Total } & \multirow{2}{*}{$\begin{array}{c}P \\
\text { value }\end{array}$} \\
\hline & & No. & $\%$ & No. & $\%$ & & \\
\hline 1. & $<1$ month & 7 & 37 & 12 & 63 & 19 & \multirow{4}{*}{0.09} \\
\hline 2. & 1-6 month & 19 & 45 & 23 & 55 & 42 & \\
\hline 3. & $>6$ month & 25 & 64 & 14 & 36 & 39 & \\
\hline & Total & 51 & 51 & 49 & 49 & 100 & \\
\hline \multicolumn{8}{|c|}{ Chi-square test used } \\
\hline
\end{tabular}

Table 3: Association of IDH-1 expression with clinical features.

\begin{tabular}{|c|c|c|c|c|c|c|c|}
\hline \multirow{2}{*}{ No. } & \multirow{2}{*}{$\begin{array}{l}\text { Clinical } \\
\text { features }\end{array}$} & \multicolumn{2}{|c|}{ Expression } & \multicolumn{2}{|c|}{ No expression } & \multirow{2}{*}{ Total } & \multirow{2}{*}{$\begin{array}{c}\mathbf{P} \\
\text { value }\end{array}$} \\
\hline & & No. & $\%$ & No. & $\%$ & & \\
\hline \multirow{4}{*}{1.} & \multicolumn{7}{|c|}{ Seizure } \\
\hline & Present & 27 & 71 & 11 & 29 & 38 & 0.002 \\
\hline & Absent & 24 & 39 & 38 & 61 & 62 & \\
\hline & Total & 51 & 51 & 49 & 49 & 100 & \\
\hline \multirow{4}{*}{2.} & \multicolumn{7}{|c|}{ Raised ICP } \\
\hline & Present & 24 & 52 & 22 & 48 & 46 & 0.828 \\
\hline & Absent & 27 & 50 & 27 & 50 & 54 & \\
\hline & Total & 51 & 51 & 49 & 49 & 100 & \\
\hline \multirow{4}{*}{3.} & \multicolumn{7}{|c|}{ Neurological deficit } \\
\hline & Present & 27 & 46 & 32 & 54 & 59 & 0.209 \\
\hline & Absent & 24 & 59 & 17 & 41 & 41 & \\
\hline & Total & 51 & 51 & 49 & 49 & 100 & \\
\hline
\end{tabular}

Table 4: Association of IDH-1 expression with tumor location.

\begin{tabular}{|c|c|c|c|c|c|c|c|c|}
\hline \multirow{2}{*}{ No. } & \multirow{2}{*}{ Tumor location } & \multicolumn{2}{|c|}{ Expression } & \multicolumn{2}{|c|}{ No expression } & \multirow{2}{*}{ Total } & \multirow{2}{*}{$P$ value } & \multirow{2}{*}{$P$ value } \\
\hline & & No. & $\%$ & No. & $\%$ & & & \\
\hline 1. & Frontal & 20 & 71 & 8 & 29 & 28 & $0.023^{*}$ & \multirow{15}{*}{0.051} \\
\hline 2. & Fronto-parietal & 3 & 50 & 3 & 50 & 6 & $>0.05$ & \\
\hline 3. & Insular & 10 & 63 & 6 & 37 & 16 & $0.317^{*}$ & \\
\hline 4. & Temporal & 3 & 43 & 4 & 57 & 7 & $>0.05$ & \\
\hline 5. & Temporo-parietal & 2 & 50 & 2 & 50 & 4 & $>0.05$ & \\
\hline 6. & Parietal & 2 & 67 & 1 & 33 & 3 & $>0.05$ & \\
\hline 7. & Parieto-occipital & 1 & 25 & 3 & 75 & 4 & 0.625 & \\
\hline 8. & Posterior fossa & 2 & 25 & 6 & 75 & 8 & 0289 & \\
\hline 9. & Spine & 4 & 40 & 6 & 60 & 10 & 0.754 & \\
\hline 10. & Multicentric & 0 & 00 & 1 & 100 & 1 & - & \\
\hline 11. & Orbit & 1 & 100 & 0 & 00 & 1 & - & \\
\hline 12. & Intraventricular & 0 & 00 & 7 & 100 & 7 & - & \\
\hline 13. & Thalamus & 1 & 50 & 1 & 50 & 2 & $>0.05$ & \\
\hline 14. & Suprasellar & 1 & 50 & 1 & 50 & 2 & $>0.05$ & \\
\hline \multirow[t]{2}{*}{15.} & Corpus callosum & 1 & 100 & 00 & 00 & 1 & - & \\
\hline & Total & 51 & 51 & 49 & 49 & 100 & & \\
\hline \multicolumn{9}{|c|}{${ }^{*}$ Chi-square test used / Fisher exact test used } \\
\hline
\end{tabular}


Table 5: Association of IDH-1 expression with radiological features of glioma.

\begin{tabular}{|c|c|c|c|c|c|c|c|}
\hline \multirow{2}{*}{ No. } & \multirow{2}{*}{ Parameters } & \multicolumn{2}{|c|}{ Expression } & \multicolumn{2}{|c|}{$\begin{array}{c}\text { No } \\
\text { expression }\end{array}$} & \multirow{2}{*}{ Total } & \multirow{2}{*}{$P$ value } \\
\hline & & No. & $\%$ & No. & $\%$ & & \\
\hline \multirow{4}{*}{1.} & \multicolumn{7}{|c|}{ Contrast enhancement } \\
\hline & Present & 35 & 43 & 46 & 57 & 81 & \multirow{2}{*}{0.001} \\
\hline & Absent & 16 & 84 & 3 & 16 & 19 & \\
\hline & Total & 51 & 51 & 49 & 49 & 100 & \\
\hline \multirow{4}{*}{2.} & \multicolumn{7}{|c|}{ Calcification } \\
\hline & Present & 9 & 75 & 3 & 25 & 12 & 0.076 \\
\hline & Absent & 42 & 48 & 46 & 52 & 88 & \\
\hline & Total & 51 & 51 & 49 & 49 & 100 & \\
\hline
\end{tabular}

\begin{tabular}{|c|c|c|c|c|c|c|c|}
\hline \multirow{2}{*}{3.} & \multicolumn{8}{|c|}{ Cystic changes } \\
\cline { 2 - 8 } & Present & 19 & 47 & 21 & 53 & 40 & 0.568 \\
\cline { 2 - 8 } & Absent & 32 & 53 & 28 & 47 & 60 & \\
\cline { 2 - 8 } & Total & 51 & 51 & 49 & 49 & 100 & \\
\hline \multicolumn{8}{|c|}{ Chi-square test used } \\
\hline
\end{tabular}

Table 6: Association of IDH-1 expression with glial cell type.

\begin{tabular}{|c|c|c|c|c|c|c|c|}
\hline \multirow[t]{2}{*}{ No. } & \multirow[t]{2}{*}{ Glial cell type } & \multicolumn{2}{|c|}{ Expression } & \multicolumn{2}{|c|}{$\begin{array}{c}\text { No } \\
\text { expression }\end{array}$} & \multirow{2}{*}{ Total } & \multirow{2}{*}{$\begin{array}{c}P \\
\text { value }\end{array}$} \\
\hline & & No. & $\%$ & No. & $\%$ & & \\
\hline 1. & Astrocytic tumor & 29 & 47 & 33 & 53 & 62 & \multirow{5}{*}{0.002} \\
\hline 2. & $\begin{array}{l}\text { Oligodendroglia } \\
\text { ltumor }\end{array}$ & 15 & 79 & 4 & 21 & 19 & \\
\hline 3. & Ependymal tumor & 4 & 25 & 12 & 75 & 16 & \\
\hline 4. & Mixed glial tumor & 3 & 100 & 00 & 00 & 3 & \\
\hline & Total & 51 & 51 & 49 & 49 & 100 & \\
\hline
\end{tabular}

Table 7: Association of IDH-1 expression with glioma histological subtype.

\begin{tabular}{|c|c|c|c|c|c|c|c|c|}
\hline \multirow{2}{*}{ No. } & \multirow{2}{*}{ Histopathology } & \multicolumn{2}{|c|}{ Expression } & \multicolumn{2}{|c|}{ No expression } & \multirow{2}{*}{ Total } & \multirow{2}{*}{$P$ value } & \multirow{2}{*}{$P$ value } \\
\hline & & No. & $\%$ & No. & $\%$ & & & \\
\hline 1. & Anaplastic astrocytoma & 4 & 100 & 00 & 00 & 4 & - & \multirow{14}{*}{0.001} \\
\hline $2 .$. & Anaplastic ependymoma & 1 & 25 & 3 & 75 & 4 & 0.625 & \\
\hline 3. & Anaplastic oligoastrocytoma & 1 & 100 & 00 & 00 & 1 & - & \\
\hline 4. & Anaplastic oligodendrogliomas & 1 & 50 & 1 & 50 & 2 & $>0.05$ & \\
\hline 5. & Diffuse fibrillary astrocytoma & 10 & 67 & 5 & 33 & 15 & $0.197^{*}$ & \\
\hline 6. & Ependymoma & 2 & 25 & 6 & 75 & 8 & 0.289 & \\
\hline 7. & Gemistocytic astrocytoma & 2 & 100 & 00 & 00 & 2 & - & \\
\hline 8. & Glioblastoma & 11 & 35 & 20 & 65 & 31 & $0.131^{*}$ & \\
\hline 9. & Myxopapillaryependymoma & 1 & 33 & 2 & 67 & 3 & $>0.05$ & \\
\hline 10. & Oligoastrocytoma & 2 & 100 & 00 & 00 & 2 & - & \\
\hline 11. & Oligodendrogliomas & 14 & 82 & 3 & 18 & 17 & 0.013 & \\
\hline 12. & Pilocytic astrocytoma & 2 & 25 & 8 & 75 & 10 & 0.109 & \\
\hline 13. & Subependymoma & 00 & 00 & 1 & 100 & 1 & - & \\
\hline & Total & 51 & 51 & 49 & 49 & 100 & & \\
\hline
\end{tabular}

Table 8: Association of IDH-1 expression with WHO grade of glioma.

\begin{tabular}{|c|c|c|c|c|c|c|c|c|}
\hline \multirow{2}{*}{ No. } & \multirow{2}{*}{$\begin{array}{l}\text { WHO } \\
\text { grade }\end{array}$} & \multicolumn{2}{|c|}{ Expression } & \multicolumn{2}{|c|}{$\begin{array}{c}\text { No } \\
\text { expression }\end{array}$} & \multirow{2}{*}{ Total } & \multirow{2}{*}{$\begin{array}{c}P \\
\text { value }\end{array}$} & \multirow{2}{*}{$\begin{array}{c}P \\
\text { value }\end{array}$} \\
\hline & & No. & $\%$ & No. & $\%$ & & & \\
\hline 1. & I & 4 & 27 & 11 & 73 & 15 & $0.071^{*}$ & \multirow{5}{*}{0.002} \\
\hline $2 .$. & II & 28 & 67 & 14 & 33 & 42 & $0.031^{*}$ & \\
\hline 3. & III & 8 & 67 & 4 & 33 & 12 & $0.248^{*}$ & \\
\hline 4. & IV & 11 & 35 & 20 & 65 & 31 & $0.106^{*}$ & \\
\hline \multicolumn{2}{|c|}{ Total } & 51 & 51 & 49 & 49 & 100 & & \\
\hline
\end{tabular}

\section{Discussion}

Isocitrate dehydrogenases (IDHs) enzymes are the component of the tricarboxylic acid (TCA) cycle that convert isocitrate to $\alpha$-ketoglutarate $(\alpha-\mathrm{KG})$ with production of NADH and/or NADPH. However, IDH gene was mainly considered as "housekeeping" gene by cancer biologists with no previously defined role in cancer. It is unclear how these IDH mutations contribute to oncogenesis. One hypothesis postulates that mutated IDH- 1 converts $\alpha$-ketoglutarate to 2-hydroxyglutarate, which invariably blocks a variety of enzymes, thereby contributing to tumor development [4].

Various methods are applied for the detection of IDH-1 and/ or IDH-2 mutations in gliomas specimens including single-strand 
conformation polymorphism analysis, direct sequencing, PCRrestriction fragment length polymorphism-based assays, DNA pyrosequencing and real-time PCR with post-PCR fluorescence melting curve analysis assays. Especially, the later assays allow for rapid, inexpensive, and sensitive analysis of IDH-1 and IDH-2 mutations in routinely processed (i.e. formalin-fixed, paraffinembedded) tumor tissues, even in samples with low tumor cell content.

Currently specific and robust monoclonal antibodies are available that can be used for immunohistochemical analysis of gliomass bearing IDH-1 R132H mutation. Testing for mutations in IDH-1 or IDH-2 can now easily and effectively be performed. This mutant IDH-1 R132H protein represents the majority (90\%) of IDH mutations in gliomass.

Our study observed a higher degree of IDH-1 expression in adults (53\%) than in children (36\%), however, this difference was statistically not significant. Similar observations were also noted by Pollack [5] and Bleeker [6]. However, Antonelli [7] and Buccaliero [8] described absent IDH-1 expression in pediatric age group. This differential expression of IDH-1 among different age group suggests existence of various age related pathways of tumorigenesis.

Many studies have described that IDH-1 mutation is more common in gliomas located in frontal lobe $[9,10]$. It may be because of the fact that frontal lobe being the largest lobe, is the commonest site of gliomas. This finding was noted in our study also where $71 \%$ of all frontal lobe gliomass had IDH-1 expression and this association was statistically significant $(\mathrm{P}=0.023)$.

In our study, we have also noted that history of seizure is significantly associated with IDH-1 expression. Similar result was also observed by Stockhammer who postulated that it may be due to altered metabolic profile of IDH-1 mutated cells which have become epileptogenic [11]. As highlighted in our results that longer the duration of symptoms, higher the degree of IDH-1 expression and patients with duration of symptoms more than 6 months showed the maximum IDH-1 expression (64\%), though statistically insignificant. Thus, the present study supports that IDH-1 mutated gliomas has longer history and are slow growing.

On comparing IDH-1 expression with the radiological findings of gliomas in our cases, it was noted that absence of contrast enhancement was significantly associated with IDH-1 expression and the same observation was reported by Carrillo et al. [10].

IDH-1 expression was significantly higher in WHO grade II and III tumors in our study $(\mathrm{P}=0.008)$. Similar observations were also described by other authors [4,12-14]. Our results showed that all of our oligoastrocytomas (100\%) showed IDH-1 expression followed by oligodendroglial tumors (79\%), astrocytic tumor $(47 \%)$ and ependymal tumor (25\%). This finding was in concordance with the various other studies $[4,13,15,16]$. However, few other studies have observed almost equal frequency of IDH-1 expression in astrocytic and oligodendroglial tumors $[14,17,18]$. This discrepancy in results may be due to difference in study cohorts in terms of their histological types and grades of tumor. Presence of higher degree of IDH-1 mutation in oligodendroglial, oligoastrocytic and astrocytic tumors, as shown in our study, suggest that probably these tumors have a common glial origin.

It has been studied that IDH-1 mutation does not exist in reactive conditions related to cerebral ischemia or infarctions, viral infections, or radiation change [19]. These findings are of particular diagnostic value because they enable the distinction of reactive gliosis from low-grade diffuse astrocytoma, a diagnostically challenging task, especially in the context of small biopsy samples.

Based on pooled results from multiple studies on IDH mutated gliomas, it has been noted that IDH-1 is affected $96 \%$ of the times and IDH- 2 is affected in only $4 \%$ of cases $[12,13,20]$. Many studies have shown that IDH-1 and IDH-2 mutations are associated with a favorable prognosis and the survival of patients with the mutant form of IDH-1 in astrocytomas or oligodendrogliomass (WHO grade II-III) and glioblastomas is longer than that of their IDH-1 wild-type counterparts $[4,9,12,14,15,17,21,22]$. However, due to poor follow up data of our patients, we could not analyze survival details in our study.

Table 9 summarizes the major studies regarding the frequency of IDH-1 expression in various subtypes of gliomas. The frequency of IDH-1 expression in the various histological subtypes of gliomas was almost similar.

\section{Limitations}

Since, in the present study, the IDH-1 expression was carried out by IHC, it is important to validate the results at genomic level by gene sequencing, which was not done in our study Unfortunately, in our study, we could not analyze survival details of our patients due to poor follow up data. Moreover, small number of cases in our study is also a limiting factor.

\section{Conclusions}

Our study observed that IDH-1 mutation occurs in overall $51 \%$ of gliomas. History of seizure, frontal location and absence of contrast enhancement on radiology are significantly associated with IDH-1 expression. IDH-1 is expressed mostly in oligoastrocytic tumors followed by oligodendroglial tumors, astrocytic tumors and least expressed in ependymal tumors. IDH-1 expression is most common in WHO grade II and III gliomas and are rare in grade I gliomas.

\section{Financial support and sponsorship}

The study was funded by intramural research grant from Research cell, Sanjay Gandhi Postgraduate Institute of Medical Sciences, Lucknow, India.

\section{Acknowledgements}

The authors are thankful to Mr. R. K. Vishwakarma, Mr. Sanjay and Mr. Mahesh, Laboratory Technicians, Department of Pathology, Sanjay Gandhi Postgraduate Institute of Medical Sciences, Lucknow, 
India for performing immunohistochemistry on the surgical specimens and other technical support.

\section{References}

1. Kleihues P, Burger PC, Collines VP, Newcomb EW, Ohagi H, et al. (2000) Astrocytic tumors; Glioblastama. International Agency for Research on Cancer Press, Lyons, p. 29-39.

2. Okamoto Y, Di Patre PL, Burkhard C, Horstmann S, Jourde B, et al. (2004) Population-based study on incidence, survival rates and genetic alterations of low grade diffuse astrocytoma and oligodendrogliomas. Acta Neuropathol 108(1): 49-56

3. Figarella-Branger D, Collin C, Coulibaly B, Quilichini B, Maues De Paula A, et al. (2008) Histological and molecular classification of gliomas. Rev (Neurol) Paris 164(6-7): 505-515.

4. Yan H, Parsons DW, Jin G, McLendon R, Rasheed BA, et al. (2009) IDH1 and IDH2 mutations in gliomass. N Engl J Med 360: 765-773.

5. Pollack IF (2011) IDH-1 mutations are common in malignant gliomass arising in adolescents: A report from Children's Oncology Group. Childs Nerv Syst 27(1): 87-94

6. Bleeker FE (2009) IDH-1 mutations at residue p.R132 (IDH-1R132) occur frequently in high grade gliomas but not in other solid tumors. Hum Mutat 30(1): 7-11.

7. Antonelli M (2010) Prognostic significance of histological grading, p53 status, YKL-40 expression and IDH-1 mutation in pediatric high grade gliomass. J Neurooncol 99(2): 209-215.

8. Buccalioro AM (2012) IDH-1 mutation in pediatric gliomas: Has it a diagnostic and prognostic value? Fetal Pedia Pathol 31(5): 278-282

9. van den Bent MJ, Dubbink HJ, Marie Y, Brandes AA, Taphoorn MJ, et al. (2010) IDH1 and IDH2 mutations are prognostic but not predictive for outcome in anaplastic oligodendroglial tumors: a report of the European Organization for Research and Treatment of Cancer Brain Tumor Group. Clin Cancer Res 16(5): 1597-1604.

10. Carrillo JA (2012) Relationship between tumor enhancement, edema, IDH-1 mutational status, MGMT promotor methylation and survival in glioblastoma. Am J Neurorad 33(7): 1349-1355.

11. Stockhammer F (2012) IDH1/2 mutations in WHO grade II astrocytomas associated with localization and seizure as the initial symptom. Seizure 21(3): 194-197.
12. Ichimura K, Pearson DM, Kocialkowski S, Bäcklund LM, Chan R, et al. (2009) IDH1 mutations are present in the majority of common adult gliomass but rare in primary glioblastomas. Neuro Oncol 11(4): 341347.

13. Hartmann C, Meyer J, Balss J, Capper D, Mueller W, et al. (2009) Type and frequency of IDH-1 and IDH-2 mutations are related to astrocytic and oligodendroglial differentiation and age: a study of 1,010 diffuse gliomass. Acta Neuropathol 118(4): 469-474.

14. Sanson M, Marie Y, Paris S, Idbaih A, Laffaire J, et al. (2009) Isocitrate dehydrogenase 1 codon 132 mutation is an important prognostic biomarker in gliomass. J Clin Oncol 27(25): 4150-4154.

15. Mukasa A (2012) Significance of IDH mutations varies with tumor histology, grade and genetics in Japanese gliomas patients. 103(3): 587592

16. Horbinski C, Kofler J, Kelly LM, Murdoch GH, Nikiforova MN (2009) Diagnostic use of IDH1/2 mutation analysis in routine clinical testing of formalin-fixed, paraffin-embedded gliomas tissues. J Neuropathol Exp Neurol 68(12): 1319-1325.

17. Jha P, Suri V, Sharma V, Singh G, Sharma MC, et al. (2013) IDH1 mutations in gliomass: first series from a tertiary care centre in India with comprehensive review of literature. Neuro-Oncology 15: 718-726.

18. Felsberg J, Wolter M, Seul H (2010) Rapid and sensitive assessment of IDH-1 and IDH-2 mutation status in cerebral gliomas based on DNA pyrosequencing. Acta Neuropathol 119(4): 501-507.

19. Sonoda Y, Kumabe T, Nakamura T, Saito R, Kanamori M, et al. (2009) Analysis of IDH1 and IDH2 mutations in Japanese gliomas patients. Cancer Sci 100:1996-1998.

20. Weller M, Felsberg J, Hartmann C, Berger H, Steinbach JP, et al. (2009) Molecular predictors of progression-free and overall survival in patients with newly diagnosed glioblastoma: a prospective translational study of the German Gliomas Network. J Clin Oncol 27(34): 5743-5750.

21. Ushio-Fukai M, Nakamura Y (2008) Reactive oxygen and angiogenesis: NADPH as target for cancer therapy. Cancer Lett 266(1): 37-52.

22. Nobusawa S (2009) IDH-1 mutations as molecular signature and predictive factor for secondary glioblastoma. Clin Cancer Res 15(19): 6002-6007.
Creative Commons Attribution 4.0 International License

For possible submissions Click Here
Submit Article

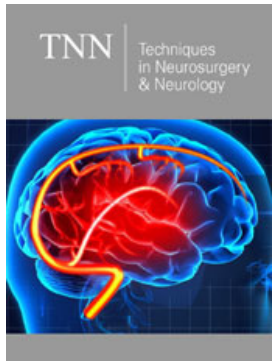

Techniques in Neurosurgery \& Neurology

\section{Benefits of Publishing with us}

- High-level peer review and editorial services

- Freely accessible online immediately upon publication

- Authors retain the copyright to their work

- Licensing it under a Creative Commons license

- Visibility through different online platforms 